\title{
Dietary supplement for relieving menopausal symptoms in Egyptian perimenopausal women
}

\author{
Salwa Mostafa El Shebini ${ }^{1 *}$ (D), Suzanne Fouad', Maha Abdel-Moaty', Nihad Hassan Ahmed', \\ Ahmed Mohamed Saied Hussein², Hend Abass Essa ${ }^{1}$ and Salwa Tawfic Tapozada'
}

\begin{abstract}
Background: Women experience various menopausal symptoms during the menopause; these symptoms can affect their quality of life and health. The aim of this study was to help females around this time to relief their symptoms by natural safe product.

Subjects and methods: Forty-two women participated as volunteers, who are suffering from different symptoms of menopause with mean age $45.36 \pm 0.98$ years. Full clinical examination, anthropometric parameters, dietary recalls, and Menopause Rating Scale evaluation were recorded. Blood sampling and biochemical analysis was done including important sex hormones. Participants daily consumed $45 \mathrm{~g}$ of supplement made from raw unsalted crashed peanut, raw sesame, dry coriander, and dry thyme that were made in the form of blend. Study period lasted for 8 weeks. Chemical composition of the blend was assessed.

Results: All participants showed marked improvement in psychological, urogenital, and somatic symptoms after intervention.

Conclusion: Data of this study showed that the blend had a beneficial impact on the physical, psychological, and mental health in perimenopausal women. So, functional foods must be considered in controlling different menopausal annoying symptoms; perimenopausal women can use this blend as a safe and effective food supplement.
\end{abstract}

Keywords: Menopausal symptoms, Menopause rating scale, Functional foods

\section{Introduction}

Female health at different age groups is an important issue to reach the efficiency of the women to perform all their duties according to their responsibilities and to increase their productive capacity which will consequently promote the national economy (Moaty et al. 2015).

One of these health problems affecting females is the menopause (time of cessation of their menstrual regularity). Women experience different menopausal symptoms during the menopausal period. These symptoms can

\footnotetext{
* Correspondence: salwasheb@hotmail.com

'Nutrition and Food Science Department, National Research Centre, Dokki, Giza, Egypt

Full list of author information is available at the end of the article
}

influence their personal satisfaction and well-being (Koo et al. 2017). Women's physical and mental ill-health, for example, anxiety and depression symptoms, hypertension, palpitations, osteoarthritis, hot flushes, and urogenital health shows an increment around the ages 45-65 years (Rindner et al. 2017).

Marjoribanks et al. (2017) reported that women with intolerable menopausal symptoms may wish to gauge the advantages of symptom relief against the total risk emerging from utilization of low-dose hormonal treatment $(\mathrm{HT})$, if they do not have contraindications to the hormonal replacement therapy. HT might be risky for certain women, including those at high risk of cardiovascular and thromboembolic diseases (for example, those 
with obesity or a past history of venous thrombosis) or risk of certain sorts of malignant growth (for example, breast or uterine cancers). The danger of endometrial malignancy among females taking estrogen as HT is recorded. Despite the fact that HT is viewed as viable for the protection of postmenopausal osteoporosis, HT is not indicated for prevention of the deterioration of cognitive function in postmenopausal women.

Dietary phytoestrogens or phytosterols have gotten expanding consideration for their impact on human well-being due to their clinical utility comparability to $17 \beta$-estradiol and, subsequently, their capacity to influence endocrine pathways (Carusi 2000; Fouad et al. 2016).

Phytoestrogens are made by plants; there are 3 classifications found in plants (isoflavones, lignans, and coumestan) (Thompson et al. 2006). Plant origin foods are rich on phytosterols especially unrefined plant oils, nuts, whole grains, vegetables, and seeds (Ostlund 2002; De Jong et al. 2003).

Peanut (Arachis hypogea L.) is a kind of nuts, which is originating in South America. Peanuts pass by an assortment of names, for example, groundnuts, earth nuts, and goobers. However, peanuts have a place with the legume family and are in this way identified with beans, lentils, and soy. In addition to the fact that peanuts taste great, they are additionally good source of protein and different nutrients (The American Peanut Council (TAPC); Peanut Facts, 2013).

Sesame ingestion has been appeared to improve blood lipids and has antioxidant properties. Sesamin a sesame lignin when reach the intestine, the intestinal microflora change it to enterolactone, a compound known to have an estrogenic action (Takemoto et al. 2015).

Thyme is an evergreen shrub that has been utilized in medicinal and culinary applications for many numbers of years. The most widely recognized form has the name Thymus vulgaris. This herb is local to the Mediterranean area and certain parts of Africa, and its utilization goes back to the Egyptian empire. The most active ingredient found in thyme is thymol. The health advantages of thyme found in its capacity to mitigate stress, improve heart health, increase the quality of the immune system, protect against chronic diseases, stimulate blood flow, and prevent fungal infections (Organic Facts 2018).

Coriander (Coriandrum sativum), an herbal plant, related to the family Apiaceae, is esteemed for its culinary and medicinal uses. All parts of this herb are being used as flavoring agent as well as conventional solutions for the treatment of various disorders in the folk medicine. Coriander contains a large number of bioactive ingredients which exhibit various pharmacological effects, as an antimicrobial, antiepileptic, antidepressant, antimutagenic, anti-inflammatory, and anxiety inhibitor. It has likewise been appeared to help lower blood pressure, blood glucose, and cholesterol to normal levels (Sahib et al. 2013).

The goal of this research was to help the female's body to adapt to lower estrogen female sex hormone round the time of the menopause, and how to eventually take control of their complaints to be relieved by a diet supplement prepared from natural available safe product.

\section{Materials and methods Subjects}

Forty-two volunteer women suffering from symptoms of menopause which were evaluated by menopause rating scale participated in this study for 8 weeks. The mean of their age was $45.36 \pm 0.98$ years. Full clinical examination and weekly follow-up were performed. Females consumed daily $45 \mathrm{~g}$ of a supplement made from raw unsalted peanut, raw sesame, dry coriander, and dry thyme that were made in the form of blend.

Ethical approval from Ethical Committee of NRC, (registration number is 16/110) and written informed consent from each of the participated women was taken.

\section{Methods}

Detailed histories for gynecological and obstetric history were taken. Full medical history and clinical examination were recorded. Relevant anthropometric measurements were reported including height, weight, waist, and hip circumferences (Jelliffe 1966). Body mass index (BMI) was calculated (weight in $\mathrm{kg} /$ height $^{2}$ in meter). Body fats (BF) as a percent from the body weight, body muscle mass, and basal metabolic rate were measured using Geratherm Body Fitness (B-5010), German.

\section{Menopause Rating Scale (MRS) evaluation form (Schneider et al. 2000).}

The MRS questionnaire has for each of the 11 item an option to check one of 5 degrees of severity of symptoms (severity 0 [none]...5 [very severe] points at the questionnaire). The calculated total score is the sum of the three-dimensional subscale scores (psychological, somatic, and urogenital subscales).

\section{Somatic symptoms}

Hot flushes, episodes of sweating, heart discomfort (unusual awareness of heart beat, heart skipping, heart racing, tightness), sleep problems (difficulty in falling asleep, difficulty in sleeping through, waking up early), and joint and muscular discomfort.

\section{Psychological symptoms}

Depressive mood (feeling down, sad, on the verge of tears, lack of drive, mood swings), irritability (feeling nervous and/or feeling aggressive), anxiety (inner 
restlessness, feeling panicky), and physical and mental exhaustion (general decrease in performance, impaired memory, decrease in concentration, forgetfulness).

\section{Urogenital symptoms}

Sexual problems (change in sexual desire, insexual activity, and satisfaction), bladder problems (difficulty in urinating, increased need to urinate, bladder incontinence), and dryness of vagina (sensation of dryness or burning in the vagina, difficulty with sexual intercourse).

\section{Blood sampling and biochemical analysis}

Fasting blood samples (after $8 \mathrm{~h}$ fasting) were drawn from the patients. Fasting blood glucose was determined on fresh samples by test strip electrochemical technology using Bayer's Contour Plus Glucometer (Clarke and Foster 2012). The rest of the blood samples were allowed to clot at the room temperature and centrifuged and sera were separated and stored at $-70{ }^{\circ} \mathrm{C}$ until used for other biochemical parameters.

Serum total cholesterol (TC), high-density lipoprotein cholesterol (HDL-C), and triglycerides (TG) were estimated by enzymatic methods using the kit supplied by Erba Mannheim ${ }^{\circ}$, Brno, CZ, (Tietz et al., 2012). Lowdensity lipoprotein cholesterol (LDL-C) was calculated according to Friedewald equation: LDL-C $(\mathrm{mg} / \mathrm{dl})=\mathrm{TC}$ - HDL-C-TG/5 (Friedewald et al. 1972). Non-HDL-C = $(\mathrm{TC})-(\mathrm{HDL}-\mathrm{C})$ risk factor $=(\mathrm{TC}) /(\mathrm{HDL}-\mathrm{C})$.

Quantitative determination of follicle stimulating hormone (FSH) concentration in participants' sera by FSH ELISA kit supplied by Chemux BioScience Inc, South San Francisco, USA, (Rebar et al. 1982).Quantitative determination of estradiol (E2) concentration by E2 ELISA kit supplied by Chemux BioScience Inc, South San Francisco, USA, (Ratcliffe et al. 1988). Quantitative determination of free testosterone concentration by Free Testosterone ELISA kit supplied by IBL International GMBH, Hamburg, Germany, (Swerdloff and Wang 2008).

\section{Dietary recalls}

Dietary recalls was performed, collecting detailed data about nutritional habits and intake through 24 recall diet history. Analysis of food items using World Food Dietary Assessment System, (WFOOD2), 1995, USA, University of California

\section{Composition of the blend}

Formula was prepared by mixing the following ingredients: raw unsalted unroasted crashed peanut, raw sesame, dry coriander, and dry thyme together as shown in Fig. 1 according to the ratio on Table 1 .

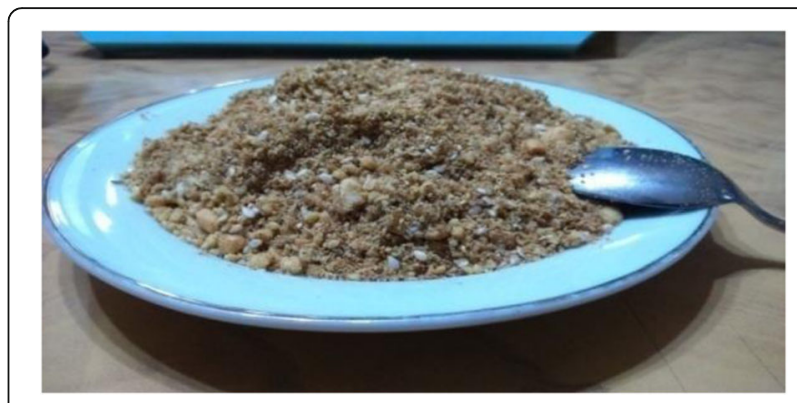

Fig. 1 Blend

\section{Chemical composition of the blend was assessed}

Ash, protein, fat, and crude fiber contents were determined in the blend according to the methods outlined in AOAC (2000). Carbohydrates were calculated by difference as mentioned as follows: carbohydrates $=100-(\%$ protein $+\%$ fat $+\%$ ash $+\%$ crude fiber). Measurement of total phenolic as tannin content was determined according to the Folin-Ciocalteu colorimetric method using spectrophotometer (Singleton and Rossi 1965).

\section{Statistical analysis}

All values were expressed as mean $\pm \mathrm{SE}$. Two-tailed student $t$ test was used to compare between data in the same group and between groups. $P$ values $<0.05$ were considered statistically significant. The SPSS window software version 17.0 (SPSS Inc. Chicago, IL, USA, 2008) was used.

\section{Results}

Table 2 showed the nutrition contents of the ingredients used and of the blend. The blend is a good source of protein, as it represents $23.04 \%$ of the total weight, making this product a rich plant-based protein source. The fat content was $31.18 \%$ and is mainly mono- and polyunsaturated fat. The blend is low in carbs $(26.79 \%)$, and it considers an excellent source of total phenolic compounds. Raw peanut or raw sesame were highly rich on fat $(46.09 \%$ and $58.30 \%$ consequently). Dry thyme and dry coriander are rich on fiber and carbohydrates.

Table 3 showed the mean \pm SD and percentage of RDAs of the habitual nutrient intake of the studied patients. The calorie consumed was mainly from fat; their diet was deficient in niacin, folic acid, vitamin $C$, vitamin $\mathrm{A}$, vitamin $\mathrm{D}$, potassium, calcium, iron, and zinc, with higher intake of sodium.

Data presented as percentage and frequency of menopausal symptoms showed in Table 4, and the mean and

Table 1 Grams of ingredient/100 grams dry weight Blend Raw crashed peanut Raw sesame Dry coriander Dry thyme
$60 \mathrm{~g}$
$20 \mathrm{~g}$
$15 \mathrm{~g}$
$5 \mathrm{~g}$ 
Table 2 Chemical composition and total phenols contents of ingredients and blend (mean \pm SE)

\begin{tabular}{lllllll}
\hline Samples & \multicolumn{5}{l}{ Approximate chemical composition } \\
\cline { 2 - 7 } & Ash (\%) & Protein (\%) & Fat (\%) & Fiber (\%) & CHO (\%) & Total phenols as tannins $(\mu \mathrm{g} / 100 \mathrm{~g})$ \\
\hline Raw crashed peanut & $1.48 \pm 0.11$ & $24.52 \pm 0.24$ & $46.09 \pm 0.48$ & $10.5 \pm 0.008$ & $17.41 \pm 0.14$ & 6969.7 \\
Raw sesame & $3.04 \pm 0.36$ & $23.18 \pm 0.20$ & $58.30 \pm 0.55$ & $7.25 \pm 0.004$ & $8.23 \pm 0.08$ & 2751.2 \\
Dry thyme & $12.32 \pm 0.54$ & $7.15 \pm 0.05$ & $3.12 \pm 0.03$ & $31.17 \pm 0.02$ & $46.24 \pm 0.42$ & 978.21 \\
Dry coriander & $9.59 \pm 0.42$ & $8.37 \pm 0.07$ & $3.02 \pm 0.03$ & $39.14 \pm 0.03$ & $39.88 \pm 0.30$ & 773.56 \\
Blend & $2.73 \pm 0.20$ & $23.04 \pm 0.21$ & $31.18 \pm 0.37$ & $16.26 \pm 0.02$ & $26.79 \pm 0.21$ & 4851.72 \\
\hline
\end{tabular}

statistical significance of total and subscales of menopausal symptoms scores found in Table 5. All participants showed marked progress in total MRS and the three subscales, psychological symptoms, urogenital symptoms, and somatic symptoms after intervention. There is a significant improvement after blend consumption. Women felt disappearance of hot flashes, night sweats, improvement of GIT symptoms especially constipation and flatulence, and psychological symptoms

Table 3 Mean \pm SE and the percentage of requirement of nutrients intake among the studied group

\begin{tabular}{|c|c|c|c|}
\hline \multirow[t]{2}{*}{ Nutrients intake } & \multicolumn{2}{|l|}{ Studied group } & \multirow[t]{2}{*}{ RDA } \\
\hline & Mean \pm SE (\% RDS) & $\%$ Calories & \\
\hline Energy (kcal) & $2195.58 \pm 10.64(99.79 \%)$ & & 2200 \\
\hline Protein (g) & $65.84 \pm 4.05(131.68 \%)$ & 12.0 & 50 \\
\hline Carbohydrate (g) & $262.60 \pm 9.67(87.53)$ & 47.85 & 300 \\
\hline Dietary fiber (g) & $23.08 \pm 1.83(92.32)$ & & 25 \\
\hline Fat ( g) & $97.98 \pm 0.49(150.74)$ & 40.17 & 65 \\
\hline SFA (g) & $33.03 \pm 0.71$ & & \\
\hline MUFA (g) & $27.28 \pm 0.55$ & & \\
\hline PUFA (g) & $29.42 \pm 0.87$ & & \\
\hline Cholesterol (mg) & $345.53 \pm 5.84(115.18 \%)$ & & 300 \\
\hline VitaminB6 (mg) & $1.94 \pm 0.12(138.57 \%)$ & & 1.4 \\
\hline VitaminB12 (mcg) & $1.87 \pm 0.09(133.57 \%)$ & & 1.4 \\
\hline Riboflavin (mg) & $1.76 \pm 0.03(146.66 \%)$ & & 1.2 \\
\hline Niacin (mg) & $10.47 \pm 0.71(80.54 \%)$ & & 13 \\
\hline Thiamin (mg) & $1.24 \pm 0.06(124.00 \%)$ & & 1.0 \\
\hline Folate(mg) & $87.53 \pm 2.27(87.53 \%)$ & & 100 \\
\hline Vitamin C (mg) & $37.30 \pm 1.05(82.89 \%)$ & & 45 \\
\hline Vitamin A $(\mu \mathrm{g})$ & $641.84 \pm 8.97(80.23 \%)$ & & 800 \\
\hline Vitamin $D(\mu \mathrm{g})$ & $2.85 \pm 0.04(57.00 \%)$ & & 5 \\
\hline Sodium (mg) & $1686 \pm 7.90(112.43 \%)$ & & 1500 \\
\hline Potassium (mg) & $1476.47 \pm 5.64(73.82 \%)$ & & 2000 \\
\hline Calcium (mg) & $621.42 \pm 3.61(62.14 \%)$ & & 1000 \\
\hline Iron (mg) & $7.06 \pm 0.61(47.07 \%)$ & & 15 \\
\hline Zinc (mg) & $7.70 \pm 0.49(64.17 \%)$ & & 12 \\
\hline
\end{tabular}

SFA Saturated fatty acid, MUFA Monounsaturated fatty acid, PUFA Polyunsaturated fatty acid such as irritability, anxiety, depression, and difficulty sleeping. Night sweats interfered with sleep and lead to chronic sleep deprivation, chronic fatigue, and mood changes.

This Table 6 showed mean \pm SE of age, anthropometric measurements, and blood pressure among the studied subjects. Most of the anthropometric measurements decreased significantly $(p<0.05-0.01)$ at the end of the diet intervention. Weight, BMI, mid waist circumference, and hip circumference decreased significantly, while the lean body masses (LBM) and the basal metabolic rate increased numerically at the end of the study. Body percentage of fat decreased without significance. Systolic blood pressure (SBP) and diastolic blood pressure (DBP) decreased significantly after supplement consumption.

Table 7 showed the mean \pm SE of the different investigated biochemical parameters. There was a decrease on the blood glucose level, LDL-C, calculated risk factor, progesterone level, and $\mathrm{FSH}$, with statistical significant difference, while HDL-C and estradiol E2 increased

Table 4 Frequency and percentage of menopausal symptoms score before and after blend consumption (no. 42)

\begin{tabular}{|c|c|c|c|c|c|}
\hline $\begin{array}{l}\text { Menopausal } \\
\text { evaluation } \\
\text { questionnaires }\end{array}$ & Score & $\begin{array}{l}\text { Frequency } \\
\text { basal }\end{array}$ & $\begin{array}{l}\text { Frequency } \\
\text { after } \\
\text { intervention }\end{array}$ & $\begin{array}{l}\text { Percentage } \\
\text { basal }\end{array}$ & $\begin{array}{l}\text { Percentage } \\
\text { after } \\
\text { intervention }\end{array}$ \\
\hline \multirow[t]{4}{*}{$\overline{M R S}$} & 1 & 9 & 33 & 21.43 & 78.57 \\
\hline & 2 & 18 & 9 & 42.86 & 21.43 \\
\hline & 3 & 12 & - & 28.57 & - \\
\hline & 4 & 3 & - & 7.14 & - \\
\hline \multirow{4}{*}{$\begin{array}{l}\text { Somatic } \\
\text { subscale }\end{array}$} & 1 & 6 & 36 & 14.29 & 85.71 \\
\hline & 2 & 15 & 6 & 35.71 & 14.29 \\
\hline & 3 & 15 & - & 35.71 & - \\
\hline & 4 & 6 & - & 14.29 & - \\
\hline \multirow{4}{*}{$\begin{array}{l}\text { Psychological } \\
\text { subscale }\end{array}$} & 1 & 12 & 33 & 28.57 & 78.57 \\
\hline & 2 & 15 & 9 & 35.71 & 21.43 \\
\hline & 3 & 12 & - & 28.57 & - \\
\hline & 4 & 3 & - & 7.14 & - \\
\hline \multirow{4}{*}{$\begin{array}{l}\text { Urogenital } \\
\text { subscale }\end{array}$} & 1 & 15 & 36 & 35.71 & 85.71 \\
\hline & 2 & 15 & 6 & 35.71 & 14.29 \\
\hline & 3 & 9 & - & 21.43 & - \\
\hline & 4 & 3 & - & 7.14 & - \\
\hline
\end{tabular}


Table 5 Mean and $p$ value of menopausal symptoms score before and after blend consumption

\begin{tabular}{ll}
\hline Parameters & Mean \pm SE \\
\hline MRS1 & $21.64 \pm 1.44$ \\
MRS2 & $7.36 \pm 0.89$ \\
Somatic1 & $9.14 \pm 0.60$ \\
Somatic2 & $3.00 \pm 0.34$ \\
Psych1 & $7.36 \pm 0.53$ \\
Psych2 & $3.07 \pm 0.42$ \\
Urogenital1 & $5.14 \pm 0.47$ \\
Urogenital2 & $1.29 \pm 0.22$ \\
\hline 1 menopausal symptoms score before diet therapy, 2 menopausal symptoms \\
score after diet therapy
\end{tabular}

significantly. No statistical significance difference found between the levels of total cholesterol, triglyceride, and free testosterone.

Psychological, somatic, urogenital and total MRS menopause rating score: $1=$ No, $2=$ Mild, 3 = Moderate, $4=$ Severe

\section{Discussion}

Hormone treatment as a replacement therapy for the estrogen deficiency is viewed as the principal line of treatment for menopausal manifestations, for the most symptoms especially the vasomotor and night sweats. Nevertheless, many women decline it in view of their

Table 6 Mean \pm SE of age, anthropometric parameters, and blood pressure of the participants at the basal and last visit of the dietary therapy (no. 42)

\begin{tabular}{lll}
\hline Anthropometric parameters & Basal & After intervention \\
\hline Ages (year) & $45.36 \pm 0.98$ & \\
Menarche age (year) & $13.29 \pm 0.19$ & \\
Height (cm) & $155.86 \pm 0.64$ & \\
Weight (kg) & $87.25 \pm 2.03$ & $85.18 \pm 1.85^{\times x}$ \\
BMl (kg/m $\left.{ }^{2}\right)$ & $34.79 \pm 0.84$ & $33.71 \pm 0.78^{\times x}$ \\
\% Body fat & $45.69 \pm 0.73$ & $45.22 \pm 0.71$ \\
Body muscle (kg) & $42.39 \pm 0.44$ & $42.42 \pm 0.44$ \\
Body water (\%) & $39.35 \pm 0.51$ & $40.09 \pm 0.49^{x}$ \\
BMR & $2058.29 \pm 22.52$ & $2068.21 \pm 22.56$ \\
Mid waist circumference (cm) & $93.39 \pm 1.01$ & $89.95 \pm 1.08^{\times x}$ \\
Hip circumference (cm) & $113.86 \pm 1.50$ & $110.07 \pm 1.38^{x \times}$ \\
WHR (cm/cm) & $0.83 \pm 0.02$ & $0.82 \pm 0.02$ \\
SBP (mmHg) & $133.21 \pm 1.71$ & $128.57 \pm 1.30^{\times}$ \\
DBP (mmHg) & $79.64 \pm 1.71$ & $74.64 \pm 1.34^{x}$ \\
\hline
\end{tabular}

$B M I$ Body mass index, \%BF \% body fat, LBM Lean body mass, BMR Basal metabolic rate, WHR Waist hip ratio, SBP Systolic blood pressure, DBP Diastolic blood pressure

${ }^{x}$ Significant at $p<0.05$

${ }^{\mathrm{xx}}$ Significant at $p<0.01$
Table 7 Mean \pm SE of biochemical parameters of the participants at the basal and the end of the dietary therapy

\begin{tabular}{lll}
\hline Biochemical parameters & Basal & After intervention \\
\hline FBG $(\mathrm{mg} / \mathrm{dl})$ & $102.35 \pm 1.98$ & $95.00 \pm 1.59^{\mathrm{xx}}$ \\
TG $(\mathrm{mg} / \mathrm{dl})$ & $113.69 \pm 9.61$ & $112.34 \pm 4.77$ \\
VLDL-C $(\mathrm{mg} / \mathrm{dl})$ & $22.74 \pm 1.92$ & $22.47 \pm 0.95$ \\
TC $(\mathrm{mg} / \mathrm{dl})$ & $204.06 \pm 5.49$ & $198.44 \pm 4.81$ \\
LDL-C $(\mathrm{mg} / \mathrm{dl})$ & $145.63 \pm 5.53$ & $135.73 \pm 4.90^{\mathrm{x}}$ \\
HDL-C $(\mathrm{mg} / \mathrm{dl})$ & $35.69 \pm 1.01$ & $40.25 \pm 0.91^{\mathrm{xx}}$ \\
Non-HDL $(\mathrm{mg} / \mathrm{dl})$ & $168.37 \pm 5.73$ & $158.19 \pm 4.98^{\mathrm{x}}$ \\
Risk factor & $5.89 \pm 0.22$ & $5.04 \pm 0.17^{\mathrm{xx}}$ \\
FSH $(\mathrm{mll} / \mathrm{ml})$ & $34.13 \pm 4.36$ & $27.34 \pm 4.86^{\mathrm{xx}}$ \\
Progesterone $(\mathrm{ng} / \mathrm{ml})$ & $5.52 \pm 0.96$ & $1.56 \pm 0.44^{\mathrm{xx}}$ \\
Estradiol (E2) $(\mathrm{pg} / \mathrm{ml})$ & $54.54 \pm 2.21$ & $72.77 \pm 2.46^{\mathrm{xx}}$ \\
Free testosterone $(\mathrm{pg} / \mathrm{ml})$ & $1.13 \pm 0.08$ & $1.21 \pm 0.04$
\end{tabular}

FBG Fasting blood glucose, TG Triglycerides, VLDL-C Very low-density lipoprotein cholesterol, TC Total cholesterol, LDL-C Low-density lipoprotein cholesterol, HDL-C High-density lipoprotein cholesterol, FSH Follicle stimulating hormone

${ }^{\mathrm{x}}$ Significant at $p<0.05 ;{ }^{\mathrm{x}}$ significant at $p<0.01$

relationship with increased danger of breast malignancy. They prefer to use plant products and dietary supplements as a line of treatment, since they are viewed as more safe products (Geller and Studee 2005; Hajirahimkhan et al. 2013; Comhaire and Depypere 2015).

The results of this study revealed that all the participants showed marked improvement in the psychological, urogenital, and somatic menopausal symptoms after blend consumption. Women felt disappearance of hot flashes, night sweats, improvement of GIT symptoms especially constipation and flatulence, and psychological symptoms such as irritability, anxiety, and difficulty sleeping, with sense of satiety leading to decrease food intake.

Functional foods contain many bioactive compounds as phytochemicals that proved their health effects (Fouad et al. 2018). Phytochemicals are results of secondary metabolism of a plant which are biologically active in humans and other animal species assuming more prominent valuable effects in health more than just nutritional properties (Gonzalez-Laredo et al. 2012).

Many epidemiological studies revealed the association between the menopausal symptoms and obesity (Koo et al. 2017). During perimenopause or postmenopause, the occurrence of low to severe symptoms is positively connected with overweight/weight (Sayón-Orea et al. 2015). Considering this condition, women shared in this study were complained from obesity where their mean BMI was $34.79 \pm 0.84$, and the mean percent body fat was $45.69 \pm 0.73$ which may related to their high daily fat intake that constitute $40.17 \%$ of their caloric intake. At the end of the intervention period, most of the 
anthropometric measurements decreased significantly ( $p$ $<0.05-0.01$ ), while the lean body mass (LBM) and the basal metabolic rate increased numerically. Therefore, decreased body weight improves quality of life in women at these stages.

Dyslipidemia is predominant in women, especially after the menopause. Raised LDL-C has been distinguished as the key lipid parameter in the two genders, while HDL-C and TG have been related, in certain studies, with cardiovascular hazard in women. Menopause has been associated with an increase of total and LDL-C and a reduce in HDL-C (prevalently in the HDL2 subfraction), (Cífková and Krajčoviechová 2015). After intervention, data of this study revealed a statistical significant decrease in the LDL-C concentration and in the same time the value of the calculated risk factor, while HDL-C increased significantly.

Significant decrease in plasma concentrations of sex hormones were observed at the menopausal period (Honour, 2018). The earlier studies concentrated on the adjustments in levels of steroid hormones and gonadotrophins and proved that follicle- stimulating hormone undergoes the principal noticeable change, while menstrual cycles stay regular (Hale and Burger 2009).

The data of this study showed that after intervention, there was statistical significant decrease in the progesterone and the FSH levels, and significant increase in the estradiol E2 concentration while no statistical significance in the levels of the free testosterone. In this context, results of a study conducted by $\mathrm{Hsu}$ et al. (2011), among Taiwanese menopausal women, were also shown elevated serum estradiol and dehydroepiandrosterone sulfate (DHEAS) levels, and decreased FSH concentration in those who ingested Diascorea (tuber contains beta-sitosterol, stigmasterol, 22-23-dihydro-, and $\gamma$-sitosterol). It has been reported that the chemical similarity between $17 \beta$-estradiol and phytoestrogens confers the capability to interact with estrogen receptors (ERs). They produce effects through genomic actions with ERs alpha and beta $(\alpha, \beta)$ or non-genomic actions via membrane G-protein receptors (GPER) such as GPR30 and mER $\alpha$ and $\operatorname{mER} \beta$ (Watson et al. 2005).

\section{Conclusion}

Data of this study showed that the blend composed of peanut, sesame, thyme, and coriander had a beneficial impact on the physical and mental ill-health in perimenopausal women. This prepared food helps in decrease bodyweight that improve quality of life in women at these stages. So the positive outcome observed in this study suggests that perimenopausal women can use this blend as a safe and effective supplement.

\section{Abbreviations}

BF: Body fats; BMl: Body mass index; BMR: Basal metabolic rate; DBP: Diastolic blood pressure; DHEAS: Dehydroepiandrosterone sulfate; E2: Estradiol; ERs: Estrogen receptors; FSH: Follicle stimulating hormone; HDL-C: High-density lipoprotein cholesterol; LBM: Lean body mass; LDL-C: Low-density lipoprotein cholesterol; MRS: Menopause rating scale; MUFA: Monounsaturated fatty acid; PUFA: Polyunsaturated fatty acid; SBP: Systolic blood pressure; SFA: Saturated fatty acid; TC: Total cholesterol; TG: Triglycerides; WHR: Waist hip ratio

\section{Acknowledgements}

The authors would like to acknowledge the volunteer females for their participation in this study. We also express our thanks to National Research Centre in Egypt, for project foundation. The project number "11010188" entitled "Dietary therapy and alternative medicine for alleviating the menopausal symptoms."

\section{Availability of data and material}

All data generated or analyzed during this study are included in this published article.

\section{Financial support}

This work was financially supported by the National Research Centre, Egypt.

\section{Significance statement}

This study revealed the importance of and the healthy beneficial effect of using functional foods in the form of dietary supplements as a dietary strategy to reduce the menopausal symptoms. This study discovers the possible synergistic effect of peanut, sesame, coriander, and thyme combination to form a blend that can be beneficial for alleviating the menopausal symptoms in Egyptian females. This study will help the physicians and the researcher to uncover the role of diet supplement significant in improvement the somatic menopausal symptoms, urogenital symptoms, and psychological symptoms after intervention.

\section{Authors' contributions}

SS designed research; SF was responsible for clinical examination,

anthropometrics measurements, and weekly follow-up; SS and SF wrote the manuscript; NH was responsible for analysis of nutritional intake and dietary habit; MM and HA had responsibility for biochemical analysis and laboratory investigations; SF and $\mathrm{NH}$ were involved in subject selections, consent signature by the subjects, and data collection; AS had the responsibility for chemical analysis of the supplement; MM was responsible for statistical analysis and revised the final manuscript; SS and ST have primary responsibility for final content. All authors read and approved the final manuscript.

\section{Ethics approval and consent to participate}

The research was given ethical approval from Ethical Committee of National Research Centre, (registration number is 16/110) and signed written informed consent from each of the volunteer women was a must to participate in the research project after they had been given a full explanation of the study.

\section{Consent for publication}

Not applicable.

\section{Competing interests}

The authors declare that there is no conflict of interests regarding the publication of this paper.

\section{Author details}

${ }^{1}$ Nutrition and Food Science Department, National Research Centre, Dokki, Giza, Egypt. ${ }^{2} F o o d$ Technology Department, National Research Centre, Dokki, Giza, Egypt.

Received: 10 September 2019 Accepted: 21 February 2020

Published online: 20 March 2020

\section{References}

AOAC (2000) Official methods of analysis of AOAC International. (17th Ed.) by Horwitz, W. Suite 500, 481 North Fredric avenue Gaithersburg, Maryland 20877-22417, USA. 
Carusi D (2000) Phytoestrogens as hormone replacement therapy: an evidence based approach. Prim Care Update Ob/Gyns 7(6):253-259

Cífková R, Krajčoviechová A (2015) Dyslipidemia and cardiovascular disease in women. Curr Cardiol Rep 17(7):609-704

Clarke F, Foster J (2012) History of blood glucose meters and their role in selfmonitoring of diabetes mellitus. Br J Biomed Sci 69(2):83-93

Comhaire FH, Depypere HT (2015) Hormones, herbal preparation and nutraceuticals for better life after the menopause: Part II. Climateric 18:364371

De Jong A, Plat J, Mensink RP (2003) Metabolic effects of plant sterols and stanols (Review). J NutrBiochem 14(7):362-369

Fouad S, El Shebini S, Moaty M, Ahmed H, Tapozada S (2016) Effect of soya beans bread fortified with turmeric or ginger on diabesity. Der PharmaChemica 8(18):398-405

Fouad S, El Shebini S, Moaty MI, Ahmed NH, Hussein AS, El Gendy A, Essa HA, Tapozada ST (2018) Nutritional supplement prepared from whole meal wheat flour, soya bean flour, flaxseed and anise seeds for alleviating the menopausal symptoms. J Biolsci 18(7):381-388

Friedewald WI, Levy RI, Fredrickson DS (1972) Estimation of the concentration of low density lipoprotein cholesterol in plasma without use of preparative ultracentrifuge. Clin Chem 18:499-502

Geller SE, Studee L (2005) Botanical and dietary supplements for menopausal symptoms what works, what does not? J Women's Health 14:634-649

Gonzalez-Laredo R, Rocha-Guzmán E, Gallegos Infante J (2012) Fitoquímicos en los alimentos In: Álvarez E, editor. Antioxidantes en alimentos y salud. México DF- Clave. Chap 6: 133-154. https://doi.org/10.5772/intechopen.69541

Hajirahimkhan A, Dietz BM, Bolton JL (2013) Botanical modulation of menopausal symptoms: mechanisms of action? Planta Medica 79:538-553

Hale GE, Burger HG (2009) Hormonal changes and biomarkers in late reproductive age, menopausal transition and menopause. Best Pract Res ClinObstetGynaecol 23(1):7-23

Honour JW (2018) Biochemistry of the menopause. Ann ClinBiochem 55(1):18-33

Hsu CC, Kuo HC, Chang SY, Wu TC, Huang KE (2011) The assessment of efficacy of Diascorea alata for menopausal symptom treatment in Taiwanese women. Climacteric 14:132-139

Jelliffe DB (1966) The assessment of the nutritional status of the community. World Health Organization Monograph, Geneva. Series No 53:50-84

Koo S, Ahn Y, Lim J, Cho J, Park H (2017) Obesity associates with vasomotor symptoms in postmenopause but with physical symptoms in perimenopause: a cross-sectional study. BMC Women's Health 17(1):126-132

Marjoribanks J, Farquhar C, Roberts H, Lethaby A, Lee J (2017) Long-term hormone therapy for perimenopausal and postmenopausal women. Cochrane Database Syst Rev 17(1):CD004143

Moaty MI, Fouad S, El Shebini SM, Kazem Y, Ahmed NH, Mohamed MS, Hussein AS, Arafa A, Hanna LM, Tapozada ST (2015) Serum ceramide kinase as a biomarker of cognitive functions, and the effect of using two slimming dietary therapies in obese middle aged females. Macedonian J Med Sci (MJMS) 3(1):18-25

Ostlund RE (2002) Phytosterols in human nutrition. Annu Rev Nutr 22:533-549

Ratcliffe WA, Carter GD, Dowsett M, Hillier SG, Middle JG, Reed MJ (1988) Oestradiol assays: applications and guidelines for the provision of a clinical biochemistry service. Ann Clin Biochem 25(Pt. 5):466-483

Rebar RW, Erickson GF, Yen SS (1982) Idiopathic premature ovarian failure: clinical and endocrine characteristics. FertilSteril 37(1):35-41

Rindner L, Strömme G, Nordeman L, Wigren M, Hange D, Gunnarsson R, Rembeck G (2017) Prevalence of somatic and urogenital symptoms as well as psychological health in women aged 45 to 55 attending primary health care: a cross-sectional study. BMC Women's Health 17(1):128-135

Sahib N, Anwar F, Gilani A, Hamid A, Saari N, Alkharfy K (2013) Coriander (Coriandrum sativum): a potential source of high-value components for functional foods and nutraceuticals. Phytother Res 27(10):1439-1456

Sayón-Orea C, Santiago S, Cuervo M, Martínez-González MA, Garcia A, Martínez JA (2015) Adherence to Mediterranean dietary pattern and menopausal symptoms in relation to overweight/obesity in Spanish perimenopausal and postmenopausal women. Menopause 22(7):750-757

Schneider H, Heinemann L, Rosemeier H, Potthoff P, Behre H (2000) The menopause rating scale (MRS): reliability of scores of menopausal complaints. Climacteric 3:59-64

Singleton VL, Rossi JR (1965) Colorimetry of total phenolics with phosphomolybdic-phosphotungstic acid. Am J EnolVitic 16:144-158
Swerdloff R, Wang C (2008) Free testosterone measurement by the analog displacement direct assay and new evidence. Clin Chem 54(3):458-460

Takemoto D, Yasutake Y, Tomimori N, Ono Y, Shibata H, Hayashi J (2015) Sesame lignans and vitamin E supplementation improve subjective statuses and antioxidative capacity in healthy humans with feelings of daily fatigue. Glob J Health Sci. 7(6):1-10

The American Peanut Council (TAPC) (2013) Peanut Facts.https://www. peanutsusa.com www.soyatech.com/peanut_facts. htm

Thompson L, Boucher B, Liu Z (2006) Phytoestrogen content of foods consumed in Canada, including isoflavones, lignans, and coumestan. Nutr Cancer 54(2): 184-201

Thyme: Benefits, history, and forms - Medical News Today. www. medicalnewstoday.com/articles/266016. Article last updated on April 11, 2018 by Organic Facts.

Tietz T, Burtis CA, Ashwood ER, Bruns DE (2012) Tietz textbook of clinical chemistry and molecular diagnostics, 5th edn. WB Saunders, Comp

Watson CS, Bulayeva NN, Wozniak AL, Finnerty CC (2005) Signaling from the membrane via membrane estrogen receptor-apha: estrogens, xenoestrogens, and phytoestrogens. Steroids 70:364-371

\section{Publisher's Note}

Springer Nature remains neutral with regard to jurisdictional claims in published maps and institutional affiliations.

\section{Submit your manuscript to a SpringerOpen ${ }^{\circ}$ journal and benefit from:}

- Convenient online submission

- Rigorous peer review

- Open access: articles freely available online

- High visibility within the field

- Retaining the copyright to your article

Submit your next manuscript at $>$ springeropen.com 